\title{
INTEGRAL DELTA DAN SIFAT-SIFATNYA
}

\author{
Delta Integral and Properties of Delta Integral
}

\author{
MOZART WINSTON TALAKUA ${ }^{1}$, MARLON STIVO NOYA VAN DELSEN ${ }^{2}$ \\ ${ }^{I}$ Staf Jurusan Matematika, FMIPA, Unpatti \\ ${ }^{2}$ Alumni Jurusan Matematika, FMIPA, Unpatti \\ Jl. Ir. M. Putuhena, Kampus Unpatti, Poka-Ambon, Maluku \\ e-mail: ocat_08@yahoo.com; marlonnvd@gmail.com
}

\begin{abstract}
Delta integral is the development of Riemann integral. The definition of Delta integral can be develop from definition of $\delta$-partition with construction and constructive definition of Riemann integral. A function $f:[a, b] \rightarrow \Re$ is said to be Riemann integralable on $[a, b]$, then it is also Delta integralable. But partition of Delta integral is refine from Riemann integral. So that the value of Delta integral function $f$ on $[a, b]$ is better with Riemann integral.
\end{abstract}

Keywords: Delta Integral, Riemann Integral, $\delta$-Cover Fill, $\delta$-Partition

\section{PENDAHULUAN}

Salah satu konsep dasar dalam matematika analisis adalah integral atau antiturunan atau antiderivatif. Ide integral sebenarnya telah muncul pada zaman Archimedes. Tetapi jika dikatakan teori integral, maka pertama kali ditemukan pada pertengahan abad ke-19. Teori integral klasik pertama kali diperkenalkan oleh Cauchy dan Riemann.

Pada tahun 1854 George F. Benhard Riemann mulai memperhalus definisi yang digunakan oleh Cauchy, dan Riemann pun mengadakan penelitian tentang integral fungsi diskontinu. Dari penelitian tersebut Riemann berhasil menemukan suatu metode khusus dari integral yang sangat mudah untuk didefinisikan, sehingga metode integral itu disebut integral Riemann, dan sebagian besar mahasiswa yang mengambil kalkulus akan mempelajari bentuk integral Riemann.

Seperti yang diketahui, setelah Riemann menemukan teori integral yang lebih baik dari teori-teori integral sebelumnya, ada banyak pengembangan penelitian dari beberapa pakar matematika yang mengakibatkan bermunculannya teori-teori integral baru yang merupakan pengembangan dari integral Riemann. Salah satu pengembangan integral Riemann adalah integral Delta yang dikembangkan oleh seorang berkebangsaan Indonesia bernama Muslich pada tahun 1997. Muslich mengembangkan tipe integral Delta dengan mencermati pengertian liput penuh- $\delta$ dan definisi konstruktif dari integral Riemann, sehingga didefinisikan teori integral Delta.

Dengan demikian dikatakan bahwa integral Delta merupakan generalisasi dari integral Riemann. Pada umumnya teori yang sering diajarkan adalah integral Riemann, padahal integral Riemann hanyalah merupakan bentuk umum dari integral Delta, dengan tujuan mendefinisikan integral Delta dan menguji sifat-sifat yang berlaku pada integral Riemann pada integral Delta.

\section{TINJAUAN PUSTAKA}

Kalkulus berhasil ditemukan sekitar tahun 1670, dan tokoh-tokoh matematika yang berperan dalam penemuan kalkulus adalah Newton dan Leibniz. Kedua tokoh ini berhasil mengembangkan teorema fundamental, yaitu yaitu mengenai anti derivative. Kemudian A. Cauchy (1789-1857) mulai mengembangkan teori tersebut, dan berhasil meneliti tentang integral dari fungsi kontinu. Pada tahun 1584, Benhard Riemann mulai memperhalus definisi yang digunakan oleh Cauchy, dan Riemann pun mengadakan penelitian tentang integral fungsi 
Diskontinu. Dari penelitian tersebut Riemann berhasil menemukan sutau metode khusus dari integral yang sangat simpel untuk didefinisikan, sehingga metode integral itu disebut Integral Riemann. Kemudian pada tahun 1875 Darboux berhasil memodifikasi integral Riemann dengan mendefinisikan Integral atas dan integral bawah sehingga terdefinisi suatu integral baru yang ekuivalen dengan integral Riemann.

Seperti yang diketahui, setelah Riemann menemukan teori integral yang lebih baik dari teori-teori integral sebelumnnya, ada banyak pengembangan penelitian dari beberapa pakar matematika yang mengakibatkan bermunculannya teori-teori integral baru yang lebih konstruktif dari integral Riemann. Teori-teori integral yang berhasil ditentukan merupakan generalisasi dari integral Riemann sehingga teori-teori tersebut sering disebut sebagai integral-integral jenis Riemann. Beberapa jenis integral Riemann terus dikaji dalam penelitianpenelitian lebih lanjut, seperti di China ada beberapa karya ilmiah yang dihasilkan Ding Chuan Song, Lu ShiPan, Ma Zhen-Min, Li Bao-Ling dan Ye Guo-Ju. Salah satu integral jenis Riemann adalah integral Delta yang dikembangkan oleh Muslich pada tahun 1997.

Dalam mengembangkan integral Delta, diperlukan definisi-definisi, teorema-teorema, dan sifat-sifat dari liput penuh- $\delta$ serta limit dan kontinu delta.

\section{Liput Penuh- $\delta$}

Diberikan konstanta $\delta>0$. Untuk setiap $\xi \in[a, b]$ dibentuk selang $D_{\xi}=(r, s)$ dengan

$$
\xi-\delta<r<\xi<s<\xi+\delta
$$

dan $D_{\xi}$ disebut selang- $\delta$ dasar di titik $\xi$. Selanjutnya dibentuk keluarga semua pasangan selang- $\delta$ dasar di titik itu, yaitu:

$$
\Delta_{\xi}=\left\{D_{\xi}=(r, s) ; \xi-\delta<r<\xi<s<\xi+\delta, \xi \in[a, b]\right\}
$$

dan $\Delta_{\xi}$ disebut sistem selang- $\delta$ dasar titik $\xi$. Sistem selang- $\delta$ dasar $\Delta_{\xi}$ ini memenuhi sifat-sifat sebagai berikut.

\section{Sifat 1}

Untuk setiap $D_{\xi} \in \Delta_{\xi}$ dan $(c, d) \subset[a, b]$ dengan $c<\xi<d$ maka berlaku $D_{\xi} \cap(c, d) \in \Delta_{\xi}$.

\section{Sifat 2}

Apabila

$$
D_{\xi}^{\prime}, D_{\xi}^{\prime \prime} \in \Delta_{\xi}
$$

maka

$D_{\xi}=\left(D_{\xi}^{\prime} \cap D_{\xi}^{\prime \prime}\right) \in \Delta_{\xi}$

\section{Sifat 3}

Apabila $D_{\xi} " \in \Delta_{\xi}$ untuk $\alpha \in A$ dan $A \neq \varnothing$, maka $D_{\xi}=\bigcup_{\alpha \in A} D_{\xi}^{\alpha} \in \Delta_{\xi}$.

\section{Sifat 4}

Untuk setiap $D_{\xi} \in \Delta_{\xi}$, maka $D_{\xi}$ memuat $\xi$ dan $u, v \in D_{\xi}$ sehingga $u<\xi<v$.

\section{Sifat 5}

Apabila $D_{\xi}=(r, s) \in \Delta_{\xi}$, maka ada $u_{1}, v_{1} \in D_{\xi}$ dengan $r<u_{1}<\xi$ dan $\xi<v_{1}<s$.

Berdasarkan definisi selang- $\delta$ dasar dapat disimpulkan bahwa untuk setiap $\xi \in[a, b]$ terdapat sistem selang- $\delta$ dasar $\Delta_{\xi}$ di titik $\xi$. Selanjutnya untuk setiap $\xi \in[a, b]$ diambil tepat satu $D_{\xi} \in \Delta_{\xi}$ dan dibangun keluarga semua $D_{\xi}$ yang disimbolir dengan:

$G=D_{\xi} ; D_{\xi} \in \Delta_{\xi}, \xi \in[a, b]$

Didefinisikan liput penuh- $\delta$ (LP- $\delta$ ) pada selang $[a, b]$ sebagai koleksi pasangan selang buka titik:

$\Delta=\left\{((u, v) ; \xi) ; u, v \in D_{\xi}, u \leq \xi \leq v, D_{\xi} \in G\right\}$

yang disebut liput penuh- $\delta$ atau disebut pula liput penuh dasar- $\Delta$ (LPD- $\Delta$ ) selang $[a, b]$, sedangkan $G$ yang membangkitkan LP- $\delta$ selang $[a, b]$ disebut pembangkit atau generator LP- $\delta$ tersebut.

Apabila $\Delta$ merupakan LP- $\delta$ selang $[a, b]$ maka partisi$\delta P$ selang $[a, b]$ didefinisikan sebagai:

$$
\begin{gathered}
P=\left\{a=x_{0}, x_{1}, x_{2}, \ldots, x_{n} ; b=\xi_{1}, \xi_{2}, \ldots, \xi_{n}\right\} \\
=\left\{\left(\left(x_{i-1}, x_{i}\right) ; \xi_{i}\right)\right\}
\end{gathered}
$$

dengan $x_{i-1}, x_{i} \in D_{\xi_{i}}, x_{i-1} \leq \xi_{i} \leq x_{i}$ dan $D_{\xi_{i}} \in \Delta$.

Teorema di bawah ini mengungkapkan eksitensi partisi- $\delta P$ selang $[a, b]$ jika diberikan LP- $\delta$.

\section{Teorema 1}

Untuk setiap LP- $\delta$ selang $[a, b]$ dapat dibangun partisi$\delta \quad P$ selang $[a, b]$ yaitu:

$P=\left\{a=x_{0}, x_{1}, x_{2}, \ldots, x_{n} ; b=\xi_{1}, \xi_{2}, \ldots, \xi_{n}\right\}$

dengan $\quad x_{i-1}, x_{i} \in D_{\xi_{i}}, \quad x_{i-1} \leq \xi_{i} \leq x_{i} \quad$ dan $\quad D_{\xi_{i}} \in \Delta$; $i=1,2, \ldots, n$.

\section{Sifat 6}

Untuk setiap generator $G$ dan $\xi \in[a, b]$ ada $r, s$ dengan $r<\xi<s$ sehingga untuk setiap $u, v \in[r, s]$ berlaku $D_{u} \cap D_{v} \neq \varnothing$ dengan $D_{u}, D_{v} \in G$.

\section{Teorema 2}

Untuk setiap liput penuh- $\delta$ selang $[a, b]$ pasti memuat partisi- $\delta$ pada setiap $[c, d] \subset[a, b]$.

\section{Teorema 3}

Jika diberikan liput penuh- $\delta_{1}, \Delta_{1}$, dan liput penuh- $\delta_{2}$, $\Delta_{2}$, dengan $\delta_{1}<\delta_{2}$ maka partisi- $\delta_{1}$ lebih halus dari partisi- $\delta_{2}$. 


\section{Sifat-sifat Dasar Integral Riemann}

Diberikan $f, g:[a, b] \rightarrow \Re$ terbatas. Jika $f, g \in R[a, b]$ dan $\alpha$ bilangan riil maka $\alpha f \in R[a, b], f+g \in R[a, b]$ dan berlaku

i. $\int_{a}^{b} \alpha f d x=\alpha \int_{a}^{b} f d x$

ii. $\int_{a}^{b}(f+g) d x=\int_{a}^{b} f d x+\int_{a}^{b} g d x$

\section{HASIL DAN PEMBAHASAN}

\section{Pengertian Dasar dan Definisi}

Diberikan konstanta $\delta>0$, dan liput liput- $\delta$ (LP- $\delta$ ) selang $[a, b]$ yaitu:

$$
\Delta=\left\{((u, v) ; \xi) ; u, v \in D_{\xi}, u \in \xi \in v, D_{\xi} \in \mathrm{G}\right\}
$$

Adapun partisi- $\delta P$ selang $[a, b]$ yang dibangun oleh liput penuh- $\delta \Delta$ didefinisikan sebagai :

$$
\begin{aligned}
P & =\left\{a=x_{0}, x_{1}, x_{2}, \ldots, x_{n}=b ; \xi_{1}, \xi_{2}, \ldots, \xi_{n}\right\} \\
& =\left\{\left(\left(x_{i-1}, x_{i}\right) ; \xi\right)\right\}
\end{aligned}
$$

dengan $\quad x_{i-1}, x_{i} \in D_{\xi} \quad$ dan $\quad x_{i-1} \leq \xi_{i} \leq x_{i} \quad$ dan $\quad$ untuk pembahasan berikutnya partisi- $\delta \quad P=\left\{\left(\left(x_{i-1}, x_{i}\right) ; \xi\right)\right\}$ cukup ditulis dengan $P=\{((u, v) ; \xi)\}$ dengan $u, v \in D_{\xi}$ dan $x_{i-1} \leq D_{\xi} \leq x_{i}$. Sedangkan eksitensi partisi- $\delta \quad P$ selang $[a, b]$ dijamin oleh Teorema 1 , dan selanjutnya Integral Delta didefinisikan dalam bentuk definisi konstruktif berdasar jumlah Riemann sebagaimana diungkap pada Definisi di bawah ini.

\section{Definisi 1 (Integral Riemann)}

Fungsi bilangan real $f:[a, b] \rightarrow \Re$ dikatakan terintegral Riemannn (terintegral-R) pada $[a, b]$ ditulis $f \in[a, b]$ jika terdapat bilangan real A sehingga untuk setiap bilangan $\varepsilon>0$ terdapat bilangan $\delta>0$ sehingga untuk setiap partisi

$$
P=\left\{a=x_{0}, x_{1}, x_{2}, \ldots, x_{n}=b ; \xi_{1}, \xi_{2}, \ldots, \xi_{n}\right\}
$$

pada $[a, b]$ yang memenuhi $x_{i-1} \leq \xi_{i} \leq x_{i}$ dan $0 \leq x_{i-1}-x_{i} \leq \delta$ untuk semua $i=1,2,3, \ldots, n$ berlaku :

$\left|(P) \sum_{i=1}^{n} f(\xi)\left(x_{i-1}-x_{i}\right)-\mathrm{A}\right|<\varepsilon$

Nilai integral Riemann fungsi $f$ pada $[a, b]$ diberikan oleh A dan dinotasikan dengan :

$A=(R) \int_{a}^{b} f d x$

\section{Definisi 2 (Integral Delta)}

Diberikan fungsi bilangan real $f:[a, b] \rightarrow \Re$ fungsi $f$ dikatakan terintegral Delta (terintegral- $R_{\delta}$ ) pada $[a, b]$ ditulis $f \in R_{\delta}[a, b]$ jika terdapat bilangan B dan liput penuh- $\delta$ sehingga untuk setiap partisi- $\delta \quad P=\{(u, v) ; \xi\}$ selang $[a, b]$ berlaku :

$$
\left|(P) \sum_{i=1}^{n} f(\xi)(u-v)-\mathrm{B}\right|<\varepsilon
$$

Bilangan B disebut nilai integral Delta (integral- $R_{\delta}$ ) fungsi $f$ pada $[a, b]$ dan dinotasikan dengan :

$$
B=\left(R_{\delta}\right) \int_{a}^{b} f d x
$$

dan jumlah $(P) \sum$ meliputi semua partisi- $\delta \quad P$ selang $[a, b]$. Pada pembahasan selanjutnya notasi $R_{\delta}[a, b]$ dimaksud himpunan semua fungsi terintegral Delta pada $[a, b]$. Teorema berikut menunjukkan bahwa nilai integral Delta fungsi $f$ pada $[a, b]$ adalah tunggal.

\section{Sifat-sifat Integral Delta}

\section{Teorema 4 (Sifat Ketunggalan)}

Diberikan fungsi bilangan real $f:[a, b] \rightarrow \Re$. Jika $f$ terintegral- $R_{\delta}$ pada $[a, b]$ maka nilai integralnya tunggal.

\section{Bukti :}

Diberikan sebarang bilangan $\varepsilon>0$. Misalkan $\mathrm{A}_{1}$ dan $\mathrm{A}_{2}$ adalah nilai integral- $R_{\delta}$ fungsi $f$ pada $[a, b]$, maka terdapat liput penuh- $\delta \quad \Delta_{1}$ selang $[a, b]$ sehingga untuk setiap partisi- $\delta \quad P_{1}=\left\{\left(\left(u^{\prime}, v^{\prime}\right) ; \xi^{\prime}\right)\right\}$ selang $[a, b]$ dengan $\left(\left(u^{\prime}, v^{\prime}\right) ; \xi^{\prime}\right) \in \Delta_{1}$ berlaku :

$$
\left|\left(P_{1}\right) \sum f\left(\xi^{\prime}\right)\left(v^{\prime}-u^{\prime}\right)-\mathrm{A}_{1}\right|<\frac{\varepsilon}{2}
$$

dan terdapat liput penuh- $\delta \quad \Delta_{2}$ selang $[a, b]$ sehingga untuk setiap partisi- $\delta \quad P_{2}=\left\{\left(\left(u^{\prime \prime}, v^{\prime \prime}\right) ; \xi "\right)\right\}$ selang $[a, b]$ dengan $\left(\left(u^{\prime \prime}, v^{\prime \prime}\right) ; \xi "\right) \in \Delta_{2}$ berlaku :

$$
\left|\left(P_{2}\right) \sum f\left(\xi^{\prime \prime}\right)\left(v^{\prime \prime}-u "\right)-\mathrm{A}_{2}\right|<\frac{\varepsilon}{2}
$$

Misalkan $\quad \Delta_{1}$ dibangkitkan oleh $\left\{D_{\varepsilon}^{\prime}\right\}$ dan $\Delta_{2}$ dibangkitkan oleh $\left\{D^{\prime \prime}{ }_{\varepsilon}\right\}$. Selanjutnya didefinisikan liput penuh- $\delta \Delta$ selang $[a, b]$ yang dibangkitkan oleh $\left\{D_{\varepsilon}\right\}$ dengan $D_{\varepsilon}=D^{\prime} \cap D^{\prime}{ }_{\varepsilon}$. Sehingga untuk setiap partisi- $\delta$ $P_{i}, i=1,2$ dan berlaku :

$$
\begin{aligned}
\left|\mathrm{A}_{1}-\mathrm{A}_{2}\right| & \leq\left|\mathrm{A}_{1}-(\mathrm{P}) \sum f(\xi)(v-\mathrm{u})+(\mathrm{P}) \sum f(\xi)(v-\mathrm{u})-\mathrm{A}_{2}\right| \\
\leq & (\mathrm{P}) \sum f(\xi)(v-\mathrm{u})-\mathrm{A}_{1}|+|(\mathrm{P}) \sum f(\xi)(v-\mathrm{u})-\mathrm{A}_{2} \mid \\
& \leq \frac{\varepsilon}{2}+\frac{\varepsilon}{2}=\varepsilon
\end{aligned}
$$

Jadi $\mathrm{A}_{1}=\mathrm{A}_{2}$. 


\section{Teorema 5 (Sifat Kelinieran)}

Diberikan fungsi bernilai real $f$ dan $g$ didefinisikan pada $[a, b]$ masing-masing terintegral- $R_{\delta}$ pada $[a, b]$ dan $\alpha \in \Re$, maka $f+g$ dan $\alpha f$ terintegral- $R_{\delta}$ pada $[a, b]$ dan berlaku:

a. $\quad\left(R_{\delta}\right) \int_{a}^{b}(f+g) d x=\left(R_{\delta}\right) \int_{a}^{b} f d x+\left(R_{\delta}\right) \int_{a}^{b} g d x$

b. $\quad\left(R_{\delta}\right) \int_{a}^{b} \alpha f d x=\alpha\left(R_{\delta}\right) \int_{a}^{b} f d x$

\section{Bukti :}

Diberikan sebarang bilangan $\varepsilon>0$.

a. Karena $f$ dan $g$ terintegral- $R_{\delta}$ pada $[a, b]$ berarti terdapat bilangan A dan terdapat liput penuh- $\delta \quad \Delta_{1}$ selang $[a, b]$ sehingga untuk setiap- $\delta$ $P_{1}=\left\{\left(\left(u^{\prime}, v^{\prime}\right) ; \xi^{\prime}\right)\right\} \quad$ selang $\quad[a, b] \quad$ dengan $\left(\left(u^{\prime}, v^{\prime}\right) ; \xi^{\prime}\right) \in \Delta_{1}$ berlaku :

\section{$\left|\left(P_{1}\right) \sum f\left(\xi^{\prime}\right)\left(v^{\prime}-u^{\prime}\right)-\mathrm{A}\right|<\frac{\varepsilon}{2}$}

dan terdapat bilangan B dan terdapat liput penuh- $\delta$ $\Delta_{2} \quad$ selang $[a, b]$ sehingga untuk setiap- $\delta$ $P_{2}=\left\{\left(\left(u^{\prime \prime}, v^{\prime \prime}\right) ; \xi^{\prime \prime}\right)\right\} \quad$ selang $\quad[a, b] \quad$ dengan $\left(\left(u^{\prime \prime}, v^{\prime \prime}\right) ; \xi "\right) \in \Delta_{2}$ berlaku :

$$
\left|\left(P_{2}\right) \sum f(\xi ")\left(v^{\prime \prime}-u^{\prime \prime}\right)-\mathrm{B}\right|<\frac{\varepsilon}{2}
$$

Misalkan $\Delta_{1}$ dibangkitkan oleh $\left\{D_{\varepsilon}^{\prime}\right\}$ dan $\Delta_{2}$ dibangkitkan oleh $\left\{D^{\prime \prime}{ }_{\varepsilon}\right\}$. Selanjutnya didefenisikan liput penuh- $\delta \quad \Delta$ selang $[a, b]$ yang dibangkitkan oleh $\left\{D_{\varepsilon}\right\}$ dengan $D_{\varepsilon}=D^{\prime} \cap D^{\prime \prime}{ }_{\varepsilon}$. Sehingga untuk setiap partisi- $\delta \quad P=\{((u, v) ; \xi)\} \quad$ selang $[a, b]$ dengan $((u, v) ; \xi) \in \Delta$ pasti merupakan partisi- $\delta$ $P_{i}, i=1,2$ dan berlaku:

$$
\begin{aligned}
& \left|(\mathrm{P}) \sum(f+g)(\xi)(v-\mathrm{u})-(\mathrm{A}+\mathrm{B})\right| \\
& \quad \leq\left|(\mathrm{P}) \sum f(\xi)(v-\mathrm{u})-\mathrm{A}\right|+\left|(\mathrm{P}) \sum g(\xi)(v-\mathrm{u})-\mathrm{B}\right| \\
& \quad \leq \frac{\varepsilon}{2}+\frac{\varepsilon}{2}=\varepsilon
\end{aligned}
$$

Jadi $f+g$ terintegral- $R_{\delta}$ pada $[a, b]$ ke bilangan $\mathrm{A}+\mathrm{B}$, sehingga

$$
\begin{aligned}
\left(R_{\delta}\right) \int_{a}^{b}(f+g) d x & =\mathrm{A}+\mathrm{B} \\
& =\left(R_{\delta}\right) \int_{a}^{b} f d x+\left(R_{\delta}\right) \int_{a}^{b} g d x
\end{aligned}
$$

b. Demikian juga berlaku :

$$
\left|(\mathrm{P}) \sum \alpha f(\xi)(v-\mathrm{u})-\alpha \mathrm{A}\right| \leq|\alpha|\left|(\mathrm{P}) \sum f(\xi)(v-\mathrm{u})-\mathrm{A}\right|
$$

$$
\leq|\alpha|+\frac{\varepsilon}{|\alpha|}=\varepsilon
$$

Jadi $\alpha f$ terintegral- $R_{\delta}$ pada $[a, b]$ ke suatu bilangan $\alpha \mathrm{A}$, sehingga

$$
\left(R_{\delta}\right) \int_{a}^{b} \alpha f d x=\alpha\left(R_{\delta}\right) \int_{a}^{b} f d x
$$

Dengan demikian Teorema 4 terbukti.

\section{Teorema 6 (Sifat Penambahan Selang)}

Diberikan fungsi bernilai real $f:[a, b] \rightarrow \mathfrak{R}$. Jika $f$ terintegral- $R_{\delta}$ pada $[a, b]$ dan $[b, c]$ maka $f$ terintegral$R_{\delta}$ pada $[a, c]$ dan berlaku:

$\left(R_{\delta}\right) \int_{a}^{b} f d x+\left(R_{\delta}\right) \int_{b}^{c} f d x=\left(R_{\delta}\right) \int_{a}^{c} f d x$

\section{Bukti :}

Diberikan sebarang bilangan $\varepsilon>0$. Misalakan $\mathrm{A}=\left(R_{\delta}\right) \int_{a}^{b} f d x$ dan $\mathrm{B}=\left(R_{\delta}\right) \int_{b}^{c} f d x$ berarti terdapat liput penuh- $\delta \quad \Delta_{1}$ selang $[a, b]$ sehingga untuk setiap- $\delta$ $P_{1}=\left\{\left(\left(u^{\prime}, v^{\prime}\right) ; \xi^{\prime}\right)\right\} \quad$ selang $\quad[a, b] \quad$ dengan $\left(\left(u^{\prime}, v^{\prime}\right) ; \xi^{\prime}\right) \in \Delta_{1}$ berlaku :

$$
\left|\left(P_{1}\right) \sum f\left(\xi^{\prime}\right)\left(v^{\prime}-u^{\prime}\right)-\mathrm{A}\right|<\frac{\varepsilon}{2}
$$

dan terdapat bilangan B dan terdapat liput penuh- $\delta \quad \Delta_{2}$ selang $[b, c]$ sehingga untuk setiap- $\delta$ $P_{2}=\left\{\left(\left(u^{\prime \prime}, v^{\prime \prime}\right) ; \xi^{\prime \prime}\right)\right\} \quad$ selang $\quad[b, c] \quad$ dengan $\left(\left(u^{\prime \prime}, v^{\prime \prime}\right) ; \xi "\right) \in \Delta_{2}$ berlaku :

$$
\left|\left(P_{2}\right) \sum f(\xi ")\left(v^{\prime \prime}-u^{\prime \prime}\right)-\mathrm{B}\right|<\frac{\varepsilon}{2}
$$

Misalkan $\Delta_{1}$ dibangkitkan oleh $\left\{D_{\varepsilon}^{\prime}\right\}$ dan $\Delta_{2}$ dibangkitkan oleh $\left\{D_{\varepsilon}^{\prime \prime}\right\}$, kemudian dibentuk liput penuh- $\delta \Delta$ selang $[a, c]$ yang dibangkitkan oleh $\left\{D_{\varepsilon}\right\}$ dengan

$$
D_{\varepsilon}=\left\{\begin{array}{l}
D_{{ }_{\varepsilon}}^{\prime} \text { jika } \xi \in[a, b) \\
D_{b} \text { jika } \xi=b \\
D_{\varepsilon}^{\prime \prime} \text { jika } \xi \in(\mathrm{b}, \mathrm{c}]
\end{array}\right.
$$

Jika $P=\left\{a=a_{0}, a_{1}, a_{2}, \ldots, a_{n}=c ; \xi_{1}, \xi_{2}, \ldots, \xi_{n}\right\}$

merupakan partisi- $\delta$ selang $[a, c]$ maka terdapat suatu $k$ , sehingga $b \in\left[a_{k-1}, a_{k}\right], k=1,2, \ldots, n$, .

Mudah dipahami bahwa:

$P^{\prime}=\left\{a=a_{0}, a_{1}, \ldots, a_{k-1}=b ; \xi_{1}, \xi_{2}, \ldots, \xi_{k-1}, b\right\}$

merupakan partisi- $\delta$ selang $[a, b]$ dengan

$$
\left(\left(u^{\prime}, v^{\prime}\right) ; \xi^{\prime}\right) \in \Delta_{1} \text { dan }
$$

$P^{\prime \prime}=\left\{b, a_{k}, a_{k+1}, \ldots,=c ; b, \xi_{k}, \xi_{k+1}, \ldots, \xi_{n}\right\}$ 
merupakan partisi- $\delta$ selang $[b, c]$ dengan

$$
\left(\left(u^{\prime \prime}, v^{\prime \prime}\right) ; \xi^{\prime \prime}\right) \in \Delta_{2} \text {. }
$$

Sehingga diperoleh :

$\left|(\mathrm{P}) \sum f(\xi)(v-\mathrm{u})-(\mathrm{A}-\mathrm{B})\right|$

$$
\begin{aligned}
& \leq\left|(\mathrm{P}) \sum f(\xi)(v-\mathrm{u})-\mathrm{A}\right|+\left|(\mathrm{P}) \sum f(\xi)(v-\mathrm{u})-\mathrm{B}\right| \\
& \leq \quad \frac{\varepsilon}{3}+\quad+\quad \frac{\varepsilon}{3}=\varepsilon
\end{aligned}
$$

Jadi terbukti bahwa $f \in R_{\delta}[a, c]$ dan berlaku :

$$
\begin{aligned}
\left(R_{\delta}\right) \int_{a}^{c} f d x & =\mathrm{A}+\mathrm{B} \\
& =\left(R_{\delta}\right) \int_{a}^{b} f d x+\left(R_{\delta}\right) \int_{b}^{c} f d x
\end{aligned}
$$

\section{Teorema 7 (Kriteria Cauchy)}

Diberikan fungsi bernilai real $f:[a, b] \rightarrow \mathfrak{R}$.

Fungsi $f \in R_{\delta}[a, b]$ jika untuk setiap bilangan $\varepsilon>0$ terdapat liput penuh- $\delta$ selang $[a, b]$ sehingga untuk setiap dua partisi- $\delta \quad P_{1}=\left\{\left(u^{\prime}, v^{\prime}\right) ; \xi\right\} \quad$ dan $P_{2}=\left\{\left(u^{\prime \prime}, v^{\prime \prime}\right) ; \xi\right\}$ selang $[a, b]$ berlaku :

$\left|P_{1} \sum f\left(\xi^{\prime}\right)\left(v^{\prime}-u^{\prime}\right)-P_{2} \sum f\left(\xi^{\prime \prime}\right)\left(v^{\prime \prime}-u^{\prime \prime}\right)\right|<\varepsilon$

\section{Bukti :}

Diberikan sebarang bilangan $\varepsilon>0$.

(i) Syarat Perlu.

Diketahui $f \in R_{\delta}[a, b]$ maka terdapat liput penuh- $\delta \Delta$ selang $[a, b]$ sehingga untuk setiap dua partisi- $\delta \quad P_{1}=\left\{\left(u^{\prime}, v^{\prime}\right) ; \xi\right\} \quad$ dan $\quad P_{2}=\left\{\left(u^{\prime \prime}, v^{\prime \prime}\right) ; \xi\right\}$ selang $[a, b]$ dengan $\left(\left(u^{\prime}, v^{\prime}\right) ; \xi\right)\left(\left(u^{\prime \prime}, v^{\prime \prime}\right) ; \xi\right) \in \Delta$ berlaku :

$$
\begin{aligned}
& \left|R_{\delta} \int_{a}^{b} f d x-P_{1} \sum f\left(\xi^{\prime}\right)\left(v^{\prime}-u^{\prime}\right)\right|<\frac{\varepsilon}{3} \\
& \left|R_{\delta} \int_{a}^{b} f d x-P_{2} \sum f\left(\xi^{\prime \prime}\right)\left(v^{\prime \prime}-u^{\prime \prime}\right)\right|<\frac{\varepsilon}{3}
\end{aligned}
$$

Sehingga diperoleh :

$$
\left|P_{1} \sum f\left(\xi^{\prime}\right)\left(v^{\prime}-u^{\prime}\right)-P_{2} \sum f\left(\xi^{\prime \prime}\right)\left(v^{\prime \prime}-u^{\prime \prime}\right)\right|
$$

$$
\begin{aligned}
& \leq\left|P_{1} \sum f\left(\xi^{\prime}\right)\left(v^{\prime}-u^{\prime}\right)-R_{\delta} \int_{a}^{b} f d x\right| \\
& \quad+\left|P_{2} \sum f\left(\xi^{\prime \prime}\right)\left(v^{\prime \prime}-u^{\prime \prime}\right)-R_{\delta} \int_{a}^{b} f d x\right| \\
& \leq \frac{\varepsilon}{3}+\frac{\varepsilon}{3}<\varepsilon
\end{aligned}
$$

(ii) Syarat Cukup.

Ambil suatu partisi- $\delta \quad P_{1}=\left\{\left(u^{\prime}, v^{\prime}\right) ; \xi\right\}$ selang $[a, b] \quad$ dengan $\quad\left(\left(u^{\prime}, v^{\prime}\right) ; \xi\right) \in \Delta \quad$ maka nilai $P_{1} \sum f\left(\xi^{\prime}\right)\left(v^{\prime}-u^{\prime}\right)$ berhingga sehingga koleksi
$\mathcal{A}=\left\{P_{1} \sum f\left(\xi^{\prime}\right)\left(v^{\prime}-u^{\prime}\right) ; P_{1}=\right.$ partisi- $\delta$ selang $\left.[a, b]\right\}$ Merupakan himpunan bilanagan real terbatas. Karena banyaknya $\mathcal{A}$ tak berhingga maka $\mathcal{A}$ mempunyai titik limit, sebut $A$. jadi diperoleh :

$\left|P_{1} \sum f\left(\xi^{\prime}\right)\left(v^{\prime}-u^{\prime}\right)-A\right|<\varepsilon$

Berarti untuk setiap partisi- $\delta \quad P=\{(u, v) ; \xi\}$ selang $[a, b]$ dengan $(u, v) ; \xi \in \Delta$ berlaku :

$$
\begin{gathered}
\left|P \sum f(\xi)(v-u)-A\right| \\
\leq\left|P \sum f(\xi)(v-u)-P_{1} \sum f\left(\xi^{\prime}\right)\left(v^{\prime}-u^{\prime}\right)\right| \\
\quad+\left|P_{1} \sum f\left(\xi^{\prime}\right)\left(v^{\prime}-u^{\prime}\right)-A\right| \\
\quad<\varepsilon+\varepsilon=2 \varepsilon \\
\text { Jadi } f \in R_{\delta}[a, b] .
\end{gathered}
$$

\section{Contoh 1}

Diberikan fungsi bernilai real $f:[0,2] \rightarrow \mathfrak{R}$ dengan

$f(x)=\left\{\begin{array}{l}1,0 \leq x<1 \\ 2,1 \leq x \leq 2\end{array}\right.$

akan ditunjukkan $f \in R_{\delta}[0,2]$.

Diberikan sebarang $\varepsilon>0$ dan ambil sebarang partisi

$$
P^{\prime}=\left\{0,1-\delta, 1+\delta, 2 ; \frac{1-\delta}{2}, \frac{2-\delta}{2}, \frac{3+\delta}{2}\right\}
$$

dan

$$
P^{\prime \prime}=\left\{0,1-2 \delta, 1+2 \delta, 2 ; \frac{1-\delta}{2}, \frac{2-\delta}{2}, \frac{3+\delta}{2}\right\}
$$

Diperoleh :

$$
\begin{aligned}
P^{\prime} \sum f\left(\xi^{\prime}\right)\left(v^{\prime}-u^{\prime}\right) & \\
= & f\left(\xi_{1}^{\prime}\right)(1-\delta-0) \\
& \quad+f\left(\xi_{2}^{\prime}\right)(1+\delta-(1-\delta))+f\left(\xi_{3}^{\prime}\right)(2-(1+\delta)) \\
= & f\left(\frac{1-\delta}{2}\right)(1-\delta)+f\left(\frac{2-\delta}{2}\right)(2 \delta)+f\left(\frac{3+\delta}{2}\right)(1-\delta) \\
= & 1(1-\delta)+1(2 \delta)+2(1-\delta) \\
= & 1-\delta+2 \delta+2-2 \delta \\
= & 3-\delta \\
P^{\prime \prime} \sum & f\left(\xi^{\prime \prime}\right)\left(v^{\prime \prime}-u^{\prime \prime}\right) \\
= & f\left(\xi_{1}^{\prime \prime}\right)(1-2 \delta-0)+f\left(\xi_{2}^{\prime \prime}\right)(1+2 \delta-(1-2 \delta)) \\
& \quad+f\left(\xi_{3}^{\prime}\right)(2-(1+2 \delta)) \\
= & f\left(\frac{1-\delta}{2}\right)(1-2 \delta)+f\left(\frac{2-\delta}{2}\right)(4 \delta) \\
& \quad+f\left(\frac{3+\delta}{2}\right)(1-2 \delta) \\
= & 1(1-2 \delta)+2(4 \delta)+2(1-2 \delta) \\
= & 1-2 \delta+8 \delta+2-4 \delta \\
= & 3+2 \delta
\end{aligned}
$$

Sehingga diperoleh

$$
\begin{aligned}
\mid P^{\prime} \sum f & \left(\xi^{\prime}\right)\left(v^{\prime}-u^{\prime}\right)-P^{\prime \prime} \sum f\left(\xi^{\prime \prime}\right)\left(v^{\prime \prime}-u^{\prime \prime}\right) \mid \\
& =|3-\delta-(3+2 \delta)| \\
& =|3-\delta-3-2 \delta|=3 \delta
\end{aligned}
$$


Dengan mengambil $\delta<\frac{\varepsilon}{3}$ maka menurut Kriteria Cauchy (Teorema 6) berakibat $f \in R_{\delta}[0,2]$.

\section{Contoh 2}

Diberikan fungsi Dirichlet $f:[0,1] \rightarrow \mathfrak{R}$ dengan $f(x)=\left\{\begin{array}{l}1, x=\text { rasional } \\ 0, x=\text { irrasional }\end{array}\right.$ akan ditunjukkan $f \in R_{\delta}[0,1]$.

Diberikan sebarang $\varepsilon>\frac{1}{2}$. Dipilih partisi- $\delta$

$$
P^{\prime}=\left\{0=x_{0}{ }^{\prime}, x_{1}{ }^{\prime}, \ldots, x_{n}{ }^{\prime}=1 ; \xi_{1}{ }^{\prime}, \xi_{2}{ }^{\prime}, \ldots, \xi_{n}{ }^{\prime}\right\}
$$

dengan $\xi_{i}{ }^{\prime}=$ rasional, dan partisi- $\delta$

$$
P^{\prime \prime}=\left\{0=x_{0} ", x_{1}{ }^{\prime}, \ldots, x_{n} "=1 ; \xi_{1} ", \xi_{2} ", \ldots, \xi_{n} "\right\}
$$

dengan $\xi_{i} "=$ irrasional.

Sehingga diperoleh:

$$
\begin{aligned}
P^{\prime} \sum f\left(\xi^{\prime}\right)\left(v^{\prime}-u^{\prime}\right) & =P^{\prime} \sum 1\left(v^{\prime}-u^{\prime}\right) \\
& =1\left(P^{\prime} \sum\left(v^{\prime}-u^{\prime}\right)\right) \\
& =1(1-0) \\
& =1 \\
P^{\prime \prime} \sum f\left(\xi^{\prime \prime}\right)\left(v^{\prime \prime}-u^{\prime \prime}\right) & =P^{\prime \prime} \sum 0\left(v^{\prime \prime}-u^{\prime \prime}\right) \\
& =0\left(P^{\prime \prime} \sum\left(v^{\prime \prime}-u^{\prime \prime}\right)\right) \\
& =0(1-0) \\
& =0
\end{aligned}
$$

dan

$\left|P^{\prime} \sum f\left(\xi^{\prime}\right)\left(v^{\prime}-u^{\prime}\right)-P^{\prime \prime} \sum f\left(\xi^{\prime \prime}\right)\left(v^{\prime \prime}-u^{\prime \prime}\right)\right|=|1-0|=1>\varepsilon$

Menurut Kriteria Cauchy berakibat $f \notin R_{\delta}[0,1]$

\section{KESIMPULAN}

Dari hasil pembahasan dan uraian pada bab-bab sebelumnya maka dapat diambil beberapa kesimpulan antara lain :

1. Diberikan fungsi bilangan riil $f:[a, b] \rightarrow \mathfrak{R}$. Fungsi $f$ dikatakan terintegral Delta (terintegral- $R_{\delta}$ ) pada $[a, b]$ ditulis $f \in R_{\delta}[a, b]$ jika terdapat bilangan $B$ dan liput penuh- $\delta$ sehingga untuk setiap partisi- $\delta$ $P=\{(u, v) ; \xi\}$ selang $[a, b]$ berlaku:

$$
\left|(P) \sum_{i=1}^{n} f(\xi)(u-v)-B\right|<\varepsilon
$$

Bilangan $B$ disebut nilai integral Delta (integral- $R_{\delta}$ ) fungsi $f$ pada $[a, b]$ dan dinotasikan dengan:

$$
B=\left(R_{\delta}\right) \int_{a}^{b} f d x
$$

Secara umum sifat-sifat dasar yang berlaku pada integral Riemann berlaku juga pada integral Delta sebagai berikut: sifat ketunggalan, kelinieran, penambahan selang dan kriteria Cauchy.

\section{DAFTAR PUSTAKA}

Gordon, R, A., (1994), The Integrals Of Lebesgue, Denjoy, Perron, and Henstock., Graduate Studies In Mathematics 4, Volume 4., American Mathematical Society.,USA.

Hutahaean, E., (1989), Analisis Real II, Penerbit Karunika, Universitas Terbuka, Jakarta.

Jain, P. K. and Gupta, V. P., (1986), Lebesgue Measure and Integration. Wiley Eastern Limited, New Delhi.

Royden, H, L., (1989), Real Analysis, Third Edition, Macmillan Publishing Company, New York.

Soeparna, D., (2006), Pengantar Analisis Real, Universitas Gajah Mada, Yogyakarta.

Soeparna, D., (2006), Pengantar Analisis Abstrak, Universitas Gajah Mada, Yogyakarta.

Muslich, (2005), Analisis Real II, Lembaga Pengembangan Pendidikan,Surakarta. 